\title{
VALUE OF BREAST ELASTOGRAPHY IN EVALUATION OF BREAST MASSES DETECTED ON SCREENING ULTRASOUND
}

\author{
By \\ Waleed Rabiey Mohammed, Amr Mahmoud Zied and Hussein Montaser \\ Roshdy \\ Department of Diagnostic and Interventional Radiology, Faculty of Medicine, Al-Azhar \\ University \\ Corresponding author: Waleed Rabiey Mohammed, \\ E-mail: waleedmohammed88@gmail.com
}

\begin{abstract}
Background: Breast cancer remains one of the leading causes of death in women over the age of 40 years. Breast cancer screening is used to identify women with asymptomatic cancer with the goal of enabling women to undergo less invasive treatments that lead to better outcomes, ideally at earlier stages, and before the cancer progresses.

Objective: To evaluate the additional value of Elastography as complementary to conventional US in breast masses found on screening US.

Patients and methods: The study was performed prospectively between April 2020 and October 2020 at Elsayed Galal University Hospital in 35 consecutive female patients with 39 breast lesions who met all inclusion criteria and no exclusion criteria.

Results: This study included 35 female patients (with 39 breast lesions). Their ages ranged from 16 to 68 years old with mean age $46 \pm 12.7$ (mean \pm SD). In this study, $8 / 39$ (20.5\%) cases were almost fatty (ACR "a") in which 6/6 cases were malignant \& 24/39 (61.5\%) with scattered area of fibro-glandular tissue (ACR "b") in which $8 / 24$ cases were malignant and $7 / 39(17.9 \%)$ cases were heterogeneously dense breasts (ACR "c") in which 3/7 cases were malignant. Lesions that scored 1, 2, and 3 were considered benign 24/39(61.5 $\%)$ cases, whereas lesions that scored 4 and 5 15/39 (38.5\%) cases, were considered malignant. When considering lesions with strain ratio less than 3.0 as benign and lesions with strain ratio more than or equal 3.0 as malignant, $15 / 39$ (38.5) lesions were benign, 24/39 (61.5\%) were malignant by strain ratio.
\end{abstract}

Conclusion: US Elastography provides useful information about distinguishing benign and malignant lesions. Thus, consideration of lesion stiffness could increase positive predictive values and reduce unnecessary benign biopsies.

Keyowrds: Breast elastography, breast masses, screening ultrasound.

\section{INTRODUCTION}

Whole-breast ultrasound (US) has been suggested to supplement mammography screening of women with dense breasts because of its improved ability to detect cancer in dense breast tissue, lack of associated ionizing radiation exposure, and its wide availability. Breast US is used primarily in the diagnostic setting to evaluate specific findings identified by physical examination or mammography. It is less widely used as a screening test in women who are at high risk for developing breast cancer and cannot 
tolerate a magnetic resonance imaging (MRI) and to date is infrequently used to screen women at on average risk (Scheel et al., 2015).

Although mammography remains the reference standard for breast cancer detection in women with dense breasts, sensitivity of mammography may decrease to as low as $30 \%-48 \%$ because non calcified breast cancers are often obscured by the surrounding and overlying dense parenchyma (Drukteinis et al., 2013).

Breast US Elastography has been used as a method for imaging tissue stiffness to improve diagnostic confidence and increase the specificity of US interpretation (Comstock, 2011).

Strain elastography (SE) produces an image based on displacement of the tissue from an external manual compression of the transducer. Because it is difficult to measure the amount of the force or stress during compression, the absolute elasticity cannot be calculated (Berg et al., 2012), and the amount of lesion deformation can be depicted only as a ratio to that of normal tissues and displayed in relative terms by gray scale or color (Comstock, 2011).

The SE features that were studied thus for include both quantitative, i.e., mean and maximum elasticity, lesion-to -fat elasticity ratio, size ratio to B-mode imaging and qualitative assessment, i.e., color assessment of maximum elasticity and homogeneity of elasticity in the mass or surrounding tissue, and several studies have shown that these elastography features can improve the specificity of Bmode US without loss of sensitivity (Berg et al., 2012).
Category 4a masses to category 3 , and a red color or stiffness greater than 160 $\mathrm{kPa}$ were sufficient criteria to upgrade BIRADS category 3 masses to category $4 a$. However, those criteria were set for breast masses detected at diagnostic US. Different guidelines may be needed for screening US-detected breast masses because most breast masses detected at screening US are small in size and relatively soft (Mahoney et al., 2012).

Multiple studies evaluating the possible role of SE in improving the accuracy of breast US have reported that breast Elastography is useful for differentiating benign from malignant breast lesions and could potentially reduce unnecessary biopsies (Athanasiou et al., 2010).

The aim of this study was to evaluate the additional value of Elastography as complementary to conventional US in breast masses found on screening US.

\section{PATIENTS AND METHODS}

The study was performed prospectively between April 2020 and October 2020 at El-Sayed Galal University Hospital in 35 consecutive female patients with 39 breast lesions who met all inclusion criteria and no exclusion criteria.

\section{The inclusion criteria were as follows:} (1) Positive ultrasound and/or mammography findings of breast masses, (2) Available histopathologic diagnosis (tru-cut needle biopsy or surgery). The local ethics committee approved the prospective design of the study and written informed consent was collected from all patients who were included in the study. 
On the other hand, exclusion criteria were as follows: (1) Lack of consent to enter the study, (2) Presence of lesions smaller than $4 \mathrm{~mm}$ or greater than $5 \mathrm{~cm}$,

(3) Presence of mastalgia or breast edema,

(4) Purely cystic lesions on conventional ultrasound examination or (5) Superficial ( $<5 \mathrm{~mm}$ deep to the skin surface), and cutaneous lesions.

Ultrasound Elastography was performed following breast ultrasound (+/- mammography) to differentiate benign from malignant masses. Data such as age, number of masses, BI-RADS category, and the longest dimension $(\mathrm{cm})$ were also noted.

\section{Conventional ultrasound examination:}

All patients were examined with Bmode ultrasound using a high-end ultrasound system (Toshiba APLIO 500) included a multi-frequency linear probe operating at 6 to $13 \mathrm{MHz}$. The scanning protocol included transverse and longitudinal real-time imaging of masses of concern. A split-screen imaging mode was used for conventional US and US elastography so as to obtain identical images optimal for accurate application for region of interest (ROI) and strain ratio (SR) measurement later on.

On B-mode ultrasonography, lesions were evaluated regarding, shape, boundary, orientation, margin, echopattern, and posterior acoustic features, presence of calcifications and surrounding tissue as well as the other features of the masses. Lesions were classified according to the American College of Radiology Breast Imaging Reporting and Data System (BI-RADS) classification as follows: category 2 lesions were classified as benign; category
3 as probably benign; category 4 as suspicious for malignancy; category 5 as highly suggestive of malignancy and category 6 lesions were pathologically proven to be malignant. BI-RADS category 4 lesions were further grouped into BI-RADS category $4 \mathrm{a}, 4 \mathrm{~b}$, and $4 \mathrm{c}$ (D'Orsi et al., 2013).

Ovoid, well-circumscribed, hypoechoic masses that had a parallel orientation to the skin were categorized as BI-RADS category 3 . The patients who had at least one suspicious finding for malignancy, such as irregular contour, microlobulation, angulation, vertical orientation to the skin, posterior acoustic shadowing, echogenic halo, or abnormal findings in the surrounding tissue were categorized as BIRADS category 4 (moderately suspicious for malignancy) and 5 (strongly suspicious for malignancy). The masses that demonstrated at least three suspicious findings for malignancy were classified as BI-RADS category 5. Lesions that could not be categorized as BI-RADS category 3 or 5 were included in BI-RADS category 4 (Costantini et al., 2010). BI-RADS category 3 and $4 a$ lesions were considered as benign, and BI-RADS category $4 b, 4 c$, and 5 lesions were considered as malignant. These data were compared with histopathological findings to calculate sensitivity, specificity, positive and negative predictive values, and accuracy.

\section{Ultrasound elastography:}

All patients were examined with ultrasound elastography. Sonoelastographic images were obtained by placing the transducer with coupling gel on the skin and then the considered mass is focused upon. 
After activating the sonoelastographic function, images were obtained by applying repeated compression and decompression in a sustained frequency. Color coding is superimposed on the translucent B-mode images. To get a correct sonoelastographic map, the process was repeated until a stable image was obtained. The sonoelastographic images were obtained in a 256-color scale ranging from red to blue. The softest component of the lesion was depicted in red, showing the greatest strain, whereas the hardest component with no strain was depicted in blue; green indicated intermediate elasticity. We selected an image obtained in the early phase of compression because these images provide the best contrast according to Itoh et al., (2010).

In the qualitative (color coded) evaluation of the sonoelastographic images, lesion classification was performed on the basis of a 5-point scoring method (Tsukuba scoring system) proposed by Itoh et al., (2010).

In the semiquantitative evaluation of the sonoelastographic images, the strain indices of the lesions were calculated. For each case, normal-appearing breast region approximately at the same level of the concerned lesion was elicited as an internal reference (channel 1) and the region of interest including the lesion was selected as (channel 2), to correctly determine the difference in hardness of the lesion compared with the surrounding normal area. The strain ratio was automatically obtained as the strain measured via channel 1/ the strain measured via channel 2 ratio.

\section{Diagnostic criteria:}

All breast lesions included in the study were classified as benign or malignant according to histopathologic findings. Histopathologic diagnoses of surgical specimens or biopsy specimens were obtained. A US-guided core-needle biopsy was performed with a Tru-Cut biopsy needle (Bard Biopsy Systems, Tempe, AZ) in patients with BI-RADS category 4 and 5 lesions within a week of the radiologic assessment by an interventional radiologist blinded to the US and RTE findings. Core biopsies were performed in patients with BI-RADS category due to the clinician's or patients' request. The patient was informed of possible risks associated with the lesion, and follow-up was recommended. Histopathologic diagnoses of BIRADS II lesions were served as reference standards. Diagnoses from elasticity scoring and the strain ratios were compared with the reference standards.

\section{Statistical analysis:}

Breast lesions were classified as malignant or benign, and RTE findings were compared. The variables were expressed as means with standard deviations, minimum and maximum values. A receiver operating characteristic curve was performed to obtain an optimal cut-off value of the strain ratio. Diagnostic test values (sensitivity, specificity, positive predictive value, negative predictive value, accuracy) with respective $95 \%$ confidential intervals were calculated. A $\mathrm{p}$ value $<0.05$ was considered significant, and analysis was bidirectional. 


\section{RESULTS}

Thirty-five female patients (with 39 breast lesions) were included in this study. Their age ranged from 16 to 68 years old with mean age $46 \pm 12.7$ (mean \pm SD) (Table 1).

Table (1): Age distribution of the patient participating in the study

\begin{tabular}{|l|c|}
\hline Age & Years \\
\hline Minimum & 16 \\
\hline Maximum & 68 \\
\hline Mean+SD & $46 \pm 12.7$ \\
\hline
\end{tabular}

Pathological Diagnoses: Breast lesions were diagnosed histologically by means of radical surgery, excisional or true cut biopsy for 20 cases (17 malignant lesions and 3 benign), In 19 benign looking lesions follow up was done after 6 months to ensure their stationary course and benignity. The final pathologic diagnoses including the total number of benign and malignant lesions (Table 2).

Table (2): Final pathological diagnoses

\begin{tabular}{|l|c|c|}
\hline \multicolumn{1}{|c|}{ Pathology } & Number & Percentage \\
\hline Benign & 22 & $56.4 \%$ \\
\hline Malignant & 17 & $43.6 \%$ \\
\hline
\end{tabular}

Benign lesions: according to sonographer picture \pm mammography and follow up except 3 cases (intraductal papillomatosis and fibroadenoma). Malignant lesions: according to histo-pathological results (Table 3).

Table (3): Final diagnoses of benign breast lesions and malignant breast lesions according to sonogram appearance, follow up and 3 cases proved by histopathology

\begin{tabular}{|c|l|c|}
\hline \multirow{2}{*}{ Variables } & $\begin{array}{c}\text { Number } \\
\text { \& percentage }\end{array}$ \\
\hline \multirow{2}{*}{$\begin{array}{c}\text { Final pathologic } \\
\text { diagnosis of benign } \\
\text { breast lesion }\end{array}$} & Fibro adenoma & $16(72.7 \%)$ \\
\cline { 2 - 3 } & Hamartoma & $2(9.1 \%)$ \\
\cline { 2 - 3 } & Intraductal papillomatosis & $3(13.6 \%)$ \\
\cline { 2 - 3 } $\begin{array}{c}\text { Final pathologic } \\
\text { diagnosis of } \\
\text { malignant breast } \\
\text { lesion }\end{array}$ & Lipoma & $1(4.5 \%)$ \\
\cline { 2 - 3 } & Invasive intraductal carcinoma & $8(47 \%)$ \\
\cline { 2 - 3 } & $\begin{array}{l}\text { Invasive lobular carcinoma } \\
\text { specified) }\end{array}$ & $5(29.4 \%)$ \\
\cline { 2 - 3 } & Follicle center cell lymphoma & $2(11.8 \%)$ \\
\cline { 2 - 3 } & Chondrosarcoma & $1(5.9 \%)$ \\
\hline
\end{tabular}

Four cases (10 \%) were diagnosed by Qualitative Elastography as benign which were diagnosed malignant by ultrasonography. After follow up and revising the pathological result, two cases were malignant (invasive lobular carcinoma and invasive intraductal carcinoma). Two cases were benign 
(intraductal papilloma and fiboadenoma)

(Table 4).

Table (4): Correlation of US BIRADS with Qualitative Elastography

\begin{tabular}{|c|c|c|c|c|c|}
\hline \multirow{2}{*}{\multicolumn{3}{|c|}{ US BIRADS *Qualitative cross tabulation }} & \multicolumn{2}{|c|}{ Qualitative } & \multirow{2}{*}{ Total } \\
\hline & & & B & $\mathrm{M}$ & \\
\hline \multirow{8}{*}{ US BIRADS } & \multirow{4}{*}{$\mathrm{B}$} & Count & 20 & $\mathbf{0}$ & 20 \\
\hline & & $\%$ within US BIRADS & $100.0 \%$ & $0.0 \%$ & $100.0 \%$ \\
\hline & & $\%$ within qualitative & $91.6 \%$ & $8.30 \%$ & $100 \%$ \\
\hline & & $\%$ of Total & $90.9 \%$ & $\mathbf{0 . 0} \%$ & $90.9 \%$ \\
\hline & \multirow{4}{*}{ M } & Count & 4 & 15 & 19 \\
\hline & & $\%$ within US BIRADS & $10.5 \%$ & $89.5 \%$ & $100.0 \%$ \\
\hline & & $\%$ within qualitative & $21 \%$ & $79.0 \%$ & $100 \%$ \\
\hline & & $\%$ of Total & $21 \%$ & $79 \%$ & $100 \%$ \\
\hline \multirow{4}{*}{\multicolumn{2}{|c|}{ Total }} & Count & 24 & 15 & 39 \\
\hline & & $\%$ within US BIRADS & $61.5 \%$ & $38.6 \%$ & $100.0 \%$ \\
\hline & & $\%$ within qualitative & $61.5 \%$ & $38.4 \%$ & $100.0 \%$ \\
\hline & & $\%$ of Total & $56.4 \%$ & $43.5 \%$ & $100.0 \%$ \\
\hline
\end{tabular}

The calculated P-value was $<0.001$.

Four cases (10\%) diagnosed by qualitative elastography as benign which are diagnosed malignant by ultrasonography. After follow up and revising the pathological result. Two cases were malignant (invasive lobular carcinoma and invasive intraductal carcinoma) (Table 5).

Table (5): Correlation of US BIRADS with Quantitative Elastography

\begin{tabular}{|c|c|c|c|c|c|}
\hline \multirow{2}{*}{\multicolumn{3}{|c|}{ US BIRADS Qualitative cross tabulation }} & \multicolumn{2}{|c|}{ Qualitative } & \multirow{3}{*}{$\begin{array}{c}\text { Total } \\
20\end{array}$} \\
\hline & & & $\mathrm{B}$ & $\mathrm{M}$ & \\
\hline \multirow{8}{*}{ US BIRADS } & \multirow{4}{*}{$\mathrm{B}$} & Count & 20 & $\mathbf{0}$ & \\
\hline & & $\%$ within US BIRADS & $100.0 \%$ & $\mathbf{0 . 0 \%}$ & $100.0 \%$ \\
\hline & & $\%$ within quantitative & $91.6 \%$ & $8.30 \%$ & $100 \%$ \\
\hline & & $\%$ of Total & $90.9 \%$ & $0.0 \%$ & $90.9 \%$ \\
\hline & \multirow{4}{*}{ M } & Count & 4 & 15 & 19 \\
\hline & & $\%$ within US BIRADS & $10.5 \%$ & $89.5 \%$ & $100.0 \%$ \\
\hline & & $\%$ within quantitative & $21 \%$ & $79.0 \%$ & $100 \%$ \\
\hline & & $\%$ of Total & $21 \%$ & $79 \%$ & $100 \%$ \\
\hline \multirow{4}{*}{\multicolumn{2}{|c|}{ Total }} & Count & 24 & 15 & 39 \\
\hline & & $\%$ within US BIRADS & $61.5 \%$ & $38.6 \%$ & $100.0 \%$ \\
\hline & & $\%$ within quantitative & $61.5 \%$ & $38.4 \%$ & $100.0 \%$ \\
\hline & & $\%$ of Total & $56.4 \%$ & $43.5 \%$ & $100.0 \%$ \\
\hline
\end{tabular}

The calculated P-value was 0.596 .

After revising pathology results of the 24 cases diagnosed as benign by Ultrasound elastography, 22 /24(91.7\%) were benign (true negative) by pathology and $2 / 24(8.3 \%)$ were malignant by pathology (false negative). After revising pathology results of the 15 cases diagnosed as malignant by Ultrasound elastography, 15/15 (100 \%) lesions confirmed to be malignant by pathology (true positive) and 0/15 (0\%) lesion were proved to be benign by pathology (false positive). The calculated sensitivity of combined elastography was $91.7 \%$, specify was $100 \%$, PPV and NPV were 
$100 \%$ and $91.7 \%$ respectively, and the total accuracy was $94.5 \%$ (Table 6).

Table (6): Correlation of combined Elastography and pathology

\begin{tabular}{|c|c|c|c|c|c|}
\hline \multirow{2}{*}{\multicolumn{3}{|c|}{$\begin{array}{c}\text { Elastography. number } * \text { Pathology Cross } \\
\text { tabulation }\end{array}$}} & \multicolumn{2}{|c|}{ Pathology } & \multirow{3}{*}{$\begin{array}{c}\text { Total } \\
24\end{array}$} \\
\hline & & & B & $\mathbf{M}$ & \\
\hline \multirow{8}{*}{$\begin{array}{l}\text { Elastography. } \\
\text { number }\end{array}$} & \multirow{4}{*}{$\mathrm{B}$} & Count & 22 & 2 & \\
\hline & & \% within Elastography.n & $91.6 \%$ & $8.4 \%$ & $100.0 \%$ \\
\hline & & $\%$ within Pathology 1 & $91.6 \%$ & $8.4 \%$ & $100 \%$ \\
\hline & & $\%$ of Total & $56.4 \%$ & $5 \%$ & $61.5 \%$ \\
\hline & \multirow{4}{*}{ M } & Count & 0 & 15 & 15 \\
\hline & & $\%$ within Elastography.n & $0 \%$ & $100 \%$ & $100.0 \%$ \\
\hline & & $\%$ within Pathology 1 & $0 \%$ & $100 \%$ & $100 \%$ \\
\hline & & $\%$ of Total & $0 \%$ & $38.4 \%$ & $38.4 \%$ \\
\hline \multirow{4}{*}{\multicolumn{2}{|c|}{ Total }} & Count & 22 & 17 & 39 \\
\hline & & $\%$ within Elastography.n & $91.6 \%$ & $8.4 \%$ & $100.0 \%$ \\
\hline & & $\%$ within Pathology & $100.0 \%$ & $100.0 \%$ & $100.0 \%$ \\
\hline & & $\%$ of Total & $56.5 \%$ & $43.5 \%$ & $100.0 \%$ \\
\hline
\end{tabular}

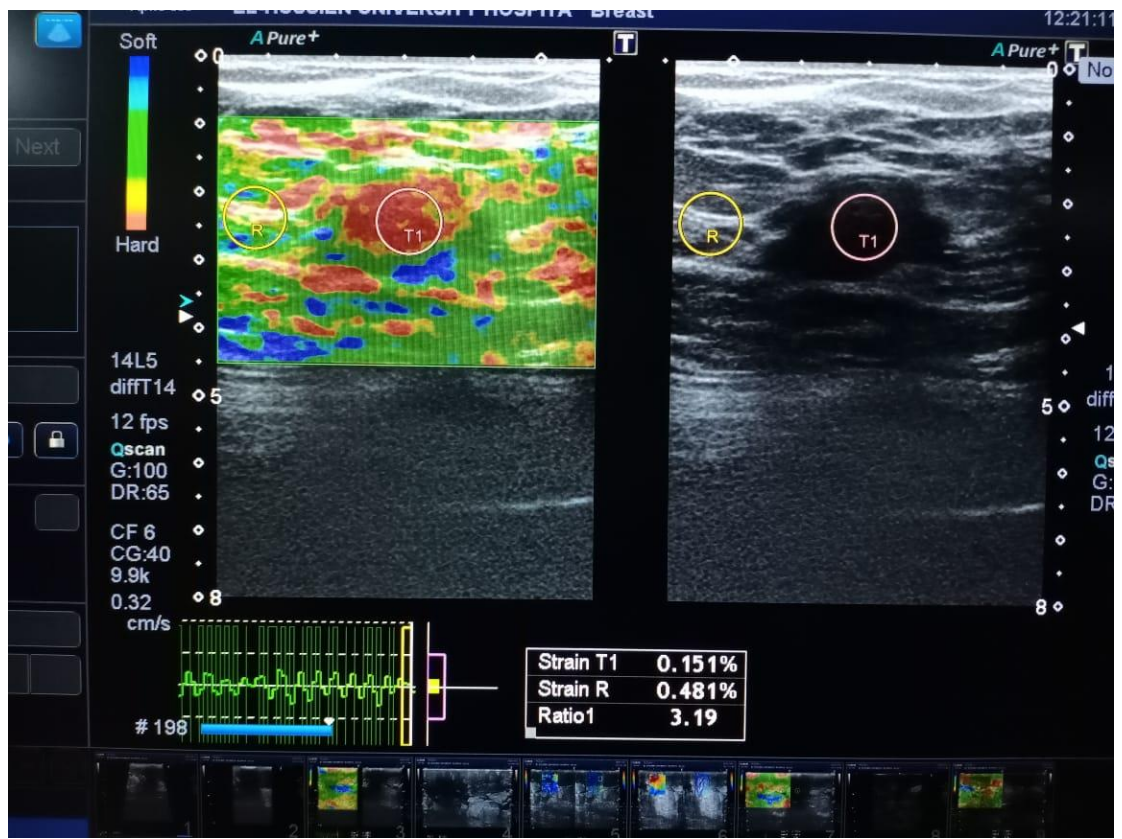

Fig. (1): Female patient 55y old, on US it was BIRADs IVc, on Qulitative elasotography it was $\mathrm{E} 2$ while on quangiative elasotography it was 4 . On revising histopathology it was malignant lesion (invasive intraductal carcinoma). 


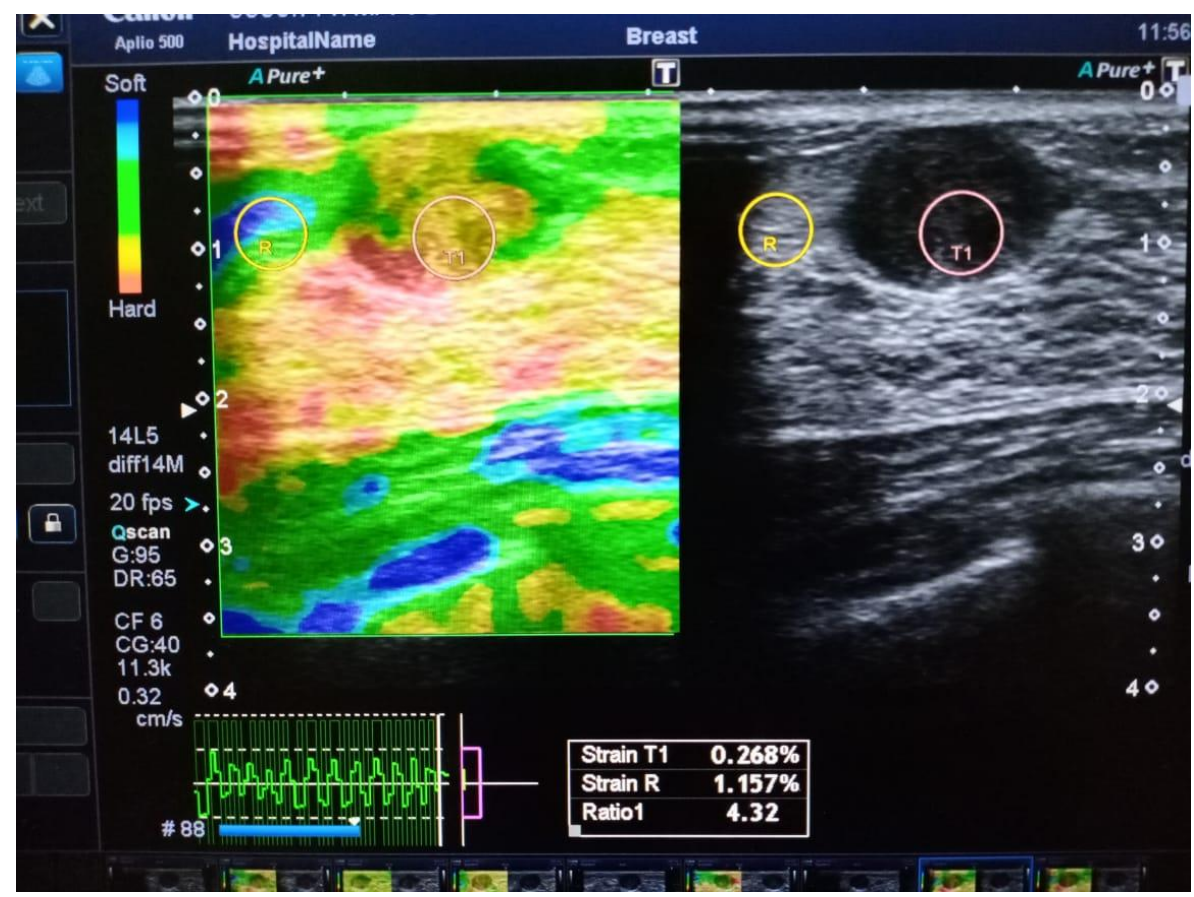

Fig. (2): Female patient 56year old, on US it was BIRADS IV, on qualitative elastography it was $\mathrm{E} 4$ while on quantiative elasography it was 4.58.after revising the histopathology it was invasive duct carcinoma.

The Histopathological part of the study was done at El-Sayed Galal University Hospital by Pro. Dr. Ibrahim Hassan

\section{DISCUSSION}

This study included 35 female patients (with 39 breast lesions), their ages ranged from 16 to 68 years old with mean age 46 \pm 12.7 (mean $\pm \mathrm{SD}$ ).

All patients underwent diagnostic Ultrasound and Elastography (Quantitative \& Qualitative)

In this study, $20.5 \%$ cases were almost fatty (ACR "a") in which $6 / 6$ cases were malignant and $61.5 \%$ with scattered area of fibro-glandular tissue (ACR "b") in which $8 / 24$ cases were malignant and (17.9 \% cases) were heterogeneously dense breasts(ACR “c”) in which 3/7 cases were malignant.

Ultrasound findings considered (51.2\% cases) listed as BIRADS II, III (benign lesions) and (48.7\% listed) as BIRADS IV, V (malignant lesions).

Qualitative Elastography, lesions that scored 1, 2, and 3 were considered benign (61.5\% cases), whereas lesions that scored 4 and 5 (38.5\% cases), were considered malignant.

Quantitative Elastography findings in this study, When considering lesions with strain ratio less than 3.0 as benign and lesions with strain ratio more than or equal 3.0 as malignant, (38.5\% lesions) were benign, $(61.5 \%)$ were malignant by strain ratio.

Ultrasound considered $(51.3 \%)$ cases as benign lesions while $(48.7 \%)$ case as malignant lesion, while Qualitative Elastography considered $(61.5 \%)$ cases as benign lesions, (38.5 \%) cases were considered malignant. 
Qualitative/ qualitative Elastography confirmed $(78.9 \%)$ of the US diagnosed malignant lesions, while ( $10.5 \%$ cases) were falsely diagnosed malignant with US which are proved benign by qualitative/ qualitative Elastography and histopathology. It falsely characterized 2 of the detected masses as benign, which proved malignant by the US and histopathology.

Elkharbotly and Farouk (2015) stated that the degree of lack of the strain of a focal lesion in breast Elastography is an important finding which improves the diagnostic reliability of Sonography, increases specificity and allows better differentiation between benign and malignant focal findings, particularly in BI-RADS- 3 and 4 lesions. Therefore, the number of false-positive findings in breast diagnostics was reduced by using Elastography.

In this study, ultrasound falsely characterized 2 of the detected masses as malignant lesions, while proved to have benign characters by Elastography and was proved to be benign by pathology (intraductal papillomatosis and fibroadenoma). Thus, Elastography helps increase specificity and limits unnecessary biopsies.

Ko et al. (2013) stated that. by using Elastography, unnecessary biopsies could be eliminated. They retrospectively reviewed that $65 \%$ were benign and $35 \%$ were malignant. When applying Elastography, $16.7 \%$ were determined to be falsely negative by Elastography. One of these lesions, which were initially classified as BI-RADS category $4 \mathrm{~b}$, was identified as ductal carcinoma in situ (DCIS), and the other which was classified as BIRADS category 5 was found to be IDC. By applying Elastography for downgrading BI-RADS category $4 \mathrm{a}$ lesions to category 3,15 unnecessary biopsies could have been eliminated from the 19 BI-RADS category 4a lesions (79 \%). For these patients, follow-up after 6 months would have been appropriate management. No cancerous lesions were missed.

Ultrasound classified $41 \%$ cases as BIRADS II, $10.3 \%$ cases as BIRADS III, $33.3 \%$ cases as BIRADS IV and $15.4 \%$ cases as BIRADS V. Elastography changed the identified BIRADS category in $10 \%$ lesions. It upgraded $5 \%$ lesions and downgraded 5\% lesions. Elastography decreased the number of BIRADS IV lesions from $33 \%$ to be $28 \%$ lesions and increased the number of BIRADS II lesions from $41 \%$ to be $46 \%$ lesions.

Yang et al. (2013) had done screening with Ultrasound and Elastography females coming for screening with ages ranging from 21 to 79 years old cases. $13.2 \%$ were malignant and $86.8 \%$ were benign. Of BIRADS category $4 \mathrm{a}$ masses, $65.5 \%$ were downgraded to category 3 .

Combined ultrasound and Elastography $89.4 \%$ lesions confirmed to be malignant by pathology (true positive) and $11.6 \%$ lesions were proved to be benign by pathology (false positive). The calculated sensitivity of ultrasound was $100 \%$, specify was $89.4 \%$, PPV and NPV were $89 \%$ and $100 \%$ respectively, the total accuracy was $94.5 \%$. On elastograph, $61.5 \%$ lesions were benign by strain ratio and $38.5 \%$ were malignant. After revising the pathology and follow up 15 lesions were true positives, 0 lesions were false positives, 2 lesions was false negative and 
22 lesions were true negatives. Elastography strain ratio (Quanlitative) had a sensitivity of $88.2 \%$, specificity of $100 \%$, PPV and NPV were $100 \%$ and 88 $\%$ respectively. The total accuracy was 93.9\%.

Ricci et al. (2017) in a study comparing the different Elastographic and conventional ultrasound in diagnostic work up of breast lesions showed that combined US and Elastography had a sensitivity of $95 \%$ and specify $70 \%$. Elkharbotly and Farouk (2015) in a study evaluating the diagnostic yield of mammography, B-mode ultrasound (US), ultrasound elastography (UE) and color Doppler used alone or in combination for differentiating breast lesions. It showed that the combined use of US and UE provided better diagnostic yield. It showed sensitivity and specificity rates $83.3 \%$ and $88.1 \%$, respectively and NPV of $92.5 \%$ and accuracy rate for diagnosis of malignancy of $86.7 \%$.

Lee et al. (2015), in a study to compare the role of elastography and conventional ultrasound in diagnostic work up of complex cystic and solid breast lesions, showed that combined US and Elastography had a sensitivity of $86.7 \%$ and specify $97.3 \%$.

Ko et al. (2013), in a study evaluating the potential role of ultrasound elastography for the differential diagnosis of breast non-mass lesions, showed that combined US and Elastography had sensitivity $83.3 \%$ and specificity of $68.2 \%$.

In our study, it was found that a combined use of conventional US and elastography can provide a correct diagnosis as US can prevent the false negative impression when elastography was used alone; more sensitive (sensitivity 100\%). The elastography can prevent false positives impressions when US was used alone; more specific (specificity $100 \%$ ).

\section{CONCLUSION}

US Elastography provides useful information about distinguishing benign and malignant lesions. Thus, consideration of lesion stiffness could increase positive predictive values and reduce unnecessary benign biopsies.

\section{REFERENCES}

1. Athanasiou A, Tardivon A, Tanter M, Sigal-Zafrani B, Bercoff $\mathbf{J}$ and Deffieux $\mathbf{T}$. (2010): Breast lesions: quantitative elastography with supersonic shear imagingpreliminary results. Radiology, 256: 297-303.

2. Berg WA, Cosgrove DO and Dore CJ. (2012): Shear-wave elastography improves the specificity of breast US: the BE1 multinational study of 939 masses. Radiology, 262(2):435-449.

3. Comstock C. (2011): Ultrasound elastography of breast lesions. Ultrasound Clin., 6: 407-415.

4. Costantini M, Belli $\mathbf{P}$ and Lombardi R. (2010): Characterization of solid breast masses use of the sonographic BI-RADS lexicon. J Ultrasound Med., 25:649-59.

5. D'Orsi CJ, Sickles EA and Mendelson EB. (2013): ACR BI-RADS ${ }^{\circledR}$ Atlas, Breast Imaging Reporting and Data System. Reston VA. American College of Radiology, 15: 3642.

6. Drukteinis JS, Mooney BP, Flowers CI and Gatenby RA. (2013): Beyond mammography: new frontiers in breast cancer screening. Am J Med., 126(6):472-9.

7. Elkharbotly $A$ and Farouk H. (2015): Ultrasound elastography improves differentiation between benign and malignant breast lumps using B-mode ultrasound and color Doppler. The Egyptian Journal of Radiology and Nuclear Medicine, 46: 12311239. 
8. Itoh A, Ueno E and Tohno E. (2010): Breast disease: Clinical application of US elastography for diagnosis. Radiology, 239:341-50.

9. Ko KH, Jung HK, Kim SJ, Kim $H$ and Yoon JH. (2013): Clinical Application of the BI-RADS Final Assessment to Breast Sonography in Conjunction with Mammography. European Society of Radiology, 15: 1209-12-15.

10. Lee BE, Chung J, Cha E, Eun J and Kim H. (2015): Role of shear-wave elastography (SWE) in complex cystic and solid breast lesions in comparison with conventional ultrasound. European Journal of Radiology, 7: 1236-1241.

11. Mahoney MC, Gatsonis $\mathrm{C}$ and Hanna $\mathrm{L}$. (2012): Positive predictive value of BI-RADS MR imaging. Radiology, 264:51-58.

12. Ricci P, Maggini E, Mancuso E, Maldur V, Medvedyva O, Ursu $S$ and Pediconi $F$.
(2017): Comparison of Ultrasound Elastography, Mammography, and Sonography in the Diagnosis of Solid Breast Lesions. Acta Radiology Journal, 10: 11891197.

13. Scheel JR, Lee JM and Sprague BL. (2015): Screening ultrasound as an adjunct to mammography in women with mammographically dense breasts. Am J Obstet Gynecol., 212:9.

14. Yang T, Liang H, Chouc C Huang J and Pan H. (2013): The adjunctive digital breast tomosynthesis in diagnosis of breast cancer. Biomed Res Int., 13: 59-63. 


\section{قيمة قياس مرونة أنسجة الثذي بالموجات الفوق صونية في تقييم أور ام الثدي المكتشفه أثناء الفحص بـان بالموجات الفوق صوتية}

وليد ربيعي محمد، عمرو محمود زايد، حبين منتصر رشدي

قسم الأشعة التثخيصية والتداخلية، كلية الطب، جامعة الأزهر

E-mail: waleedmohammed88@gmail.com

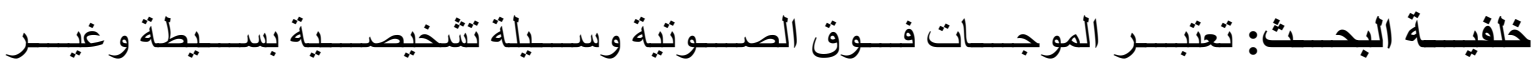

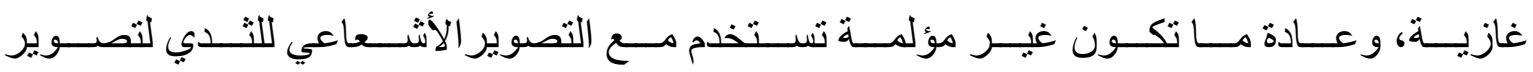

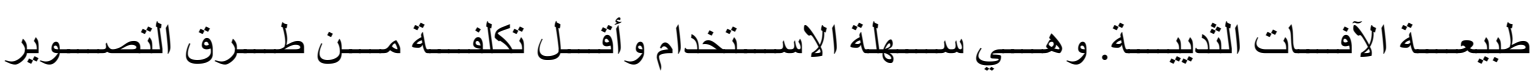

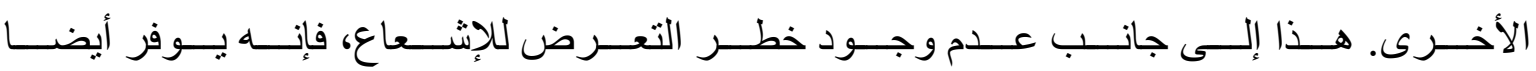

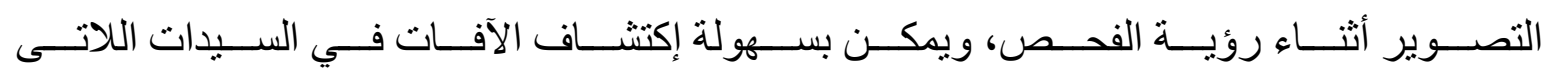
تكون أنسجة الثذي فيهن كثيفة.

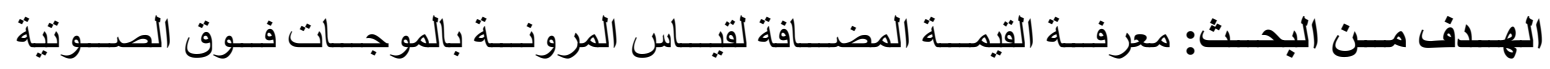
في تقييم أورام الثدى الدكتثفة أثناء الكثف المبكر للأورام الثنيية.

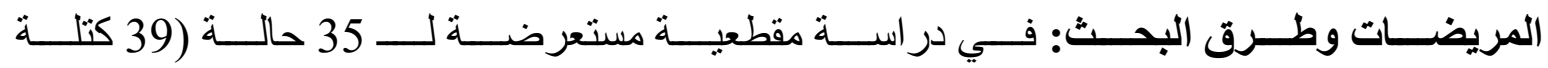

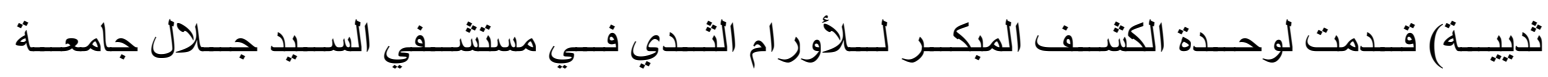

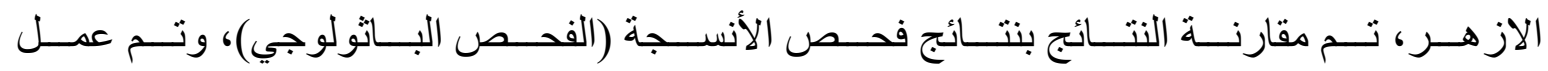

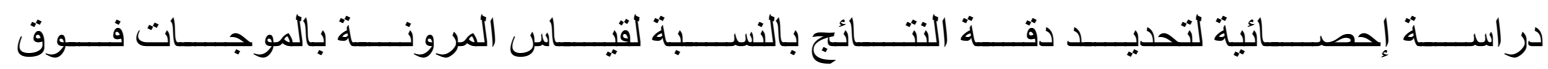

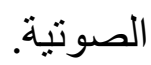

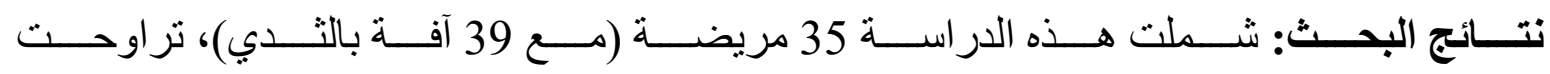

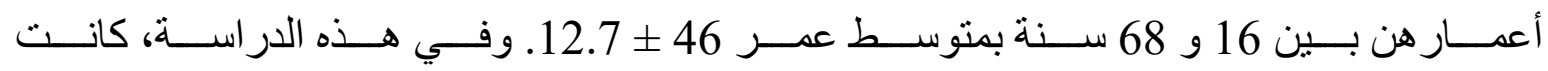

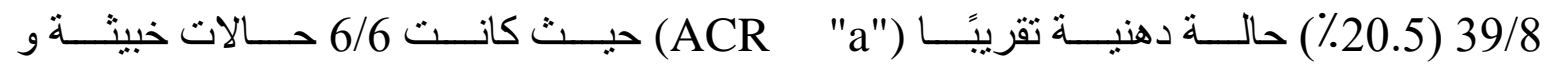

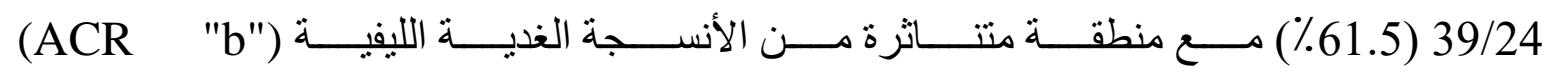

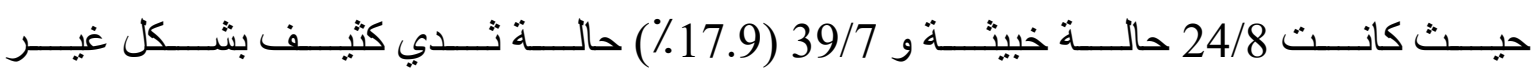

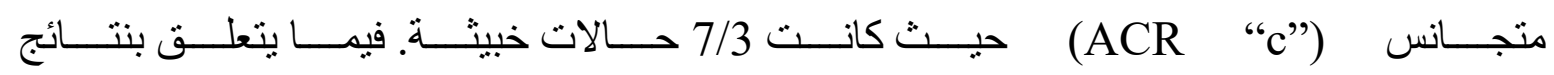

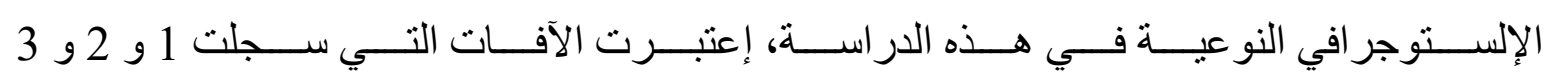




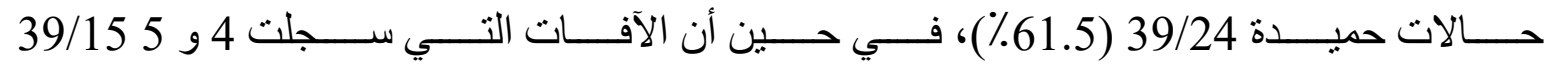

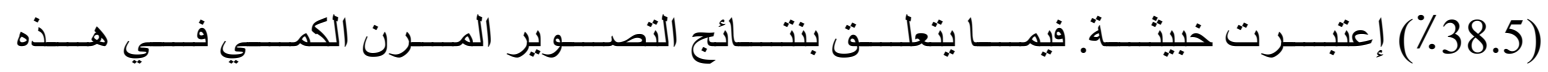

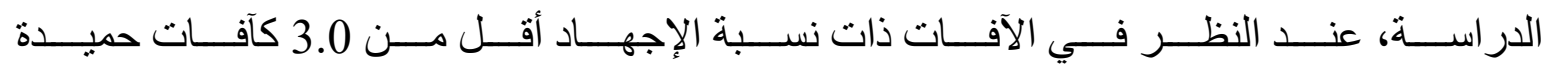

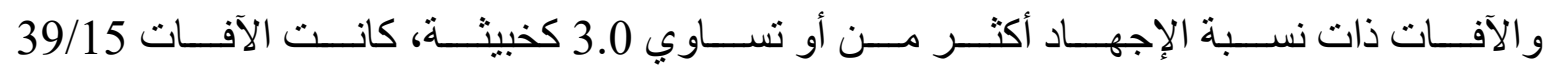
(38.5) حميدة ، 39/24 (61.5\%) كانت الخبيثة بنسبة الإجهاد.

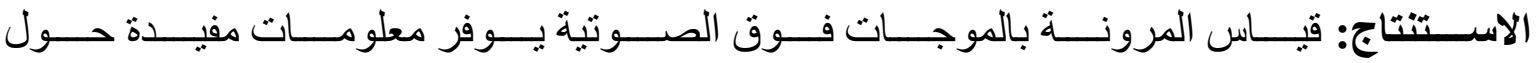

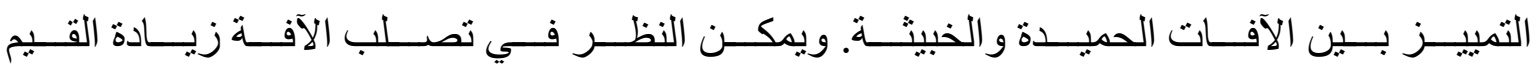

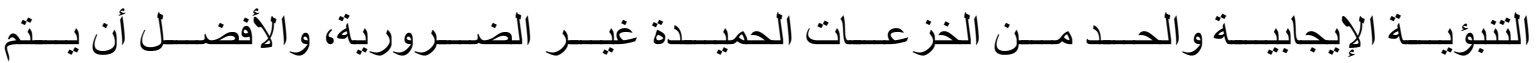

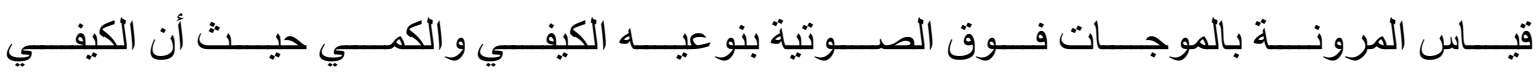

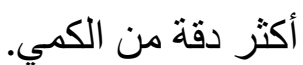

الكلمات الدالة: تصوير الثني، تكتلات الثدي، فحص الموجات فوق الصوتية. 